\title{
IN PURSUIT OF COMPARABLE CONCEPTS AND DATA ABOUT COLLECTIVE ACTION
}

\author{
Amy Poteete and Elinor Ostrom
}

International Forestry Resources and Institutions (IFRI) Research Program

Workshop in Political Theory and Policy Analysis

Indiana University

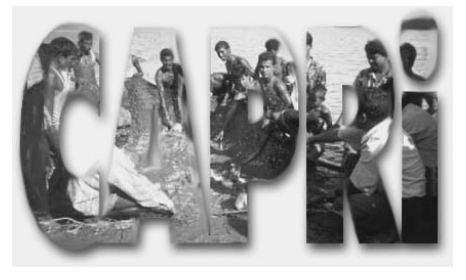

\section{CGIAR Systemwide Program on} Collective Action and Property Rights

Secretariat:

International Food Policy Research Institute

2033 K Street, N.W.

Washington, D.C. 20006 U.S.A.

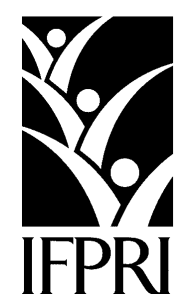

March 2003

All CAPRi Working Papers are available for download from the CAPRi web site at http://www.capri.cgiar.org.

The CAPRi Program is one of several Inter-Center Initiatives of the CGIAR and aims to promote comparative research on the role played by property and collective action institutions in shaping the efficiency, sustainability, and equity components of natural resource systems.

CAPRi Working Papers contain preliminary material and research results, and are circulated prior to a full peer review in order to stimulate discussion and critical comment. It is expected that most Working Papers will eventually be published in some other form, and that their content may also be revised. 


\begin{abstract}
Research on collective action confronts two major obstacles. First, inconsistency in the conceptualization and operationalization of collective action, the key factors expected to affect collective action, and the outcomes of collective action hampers the accumulation of knowledge. Inconsistent terminology obscures consistent patterns. Second, the scarcity of comparable data thwarts evaluation of the relative importance of the many variables identified in the literature as likely to influence collective action. The International Forestry Resources and Institutions (IFRI) research program addresses both of these problems. Since its founding in 1993, the IFRI network of collaborating research centers has used a common set of methods and concepts to study forests, the people who use forest resources, and their institutions for resource management. The basic social unit of analysis in IFRI is the user group, defined as a set of individuals with the same rights and responsibilities to forest resources. This definition does not require formal organization or collective action, since these features are potential dependent variables. This strategy for data collection allows analysis of relationships between diverse forms of social heterogeneity and collective action within groups with comparable rights to resources. IFRI's relational database also captures the connections among forest systems, sets of resource users, particular forest products, formal and informal rules for resource use, and formal local and supralocal organizations. By the middle of 2001, the IFRI database included data on 141 sites with 231 forests, 233 user groups, 94 forest organizations, and 486 products in 12 countries. Drawing upon these data, IFRI researchers are contributing substantially to our understanding of collective action for institutional development, the mediating role institutions play relative to demographic and market pressures in patterns of resource use, and relationships between particular institutions and forest conditions. The paper describes IFRI's strategy for collecting comparable data based on consistent conceptualization and operationalization, summarizes the contributions of IFRI research to the study of collective action for natural resource management, and identifies continuing challenges.
\end{abstract}

Keywords: collective action; institutions; forestry research; forestry; natural resource management 


\title{
IN PURSUIT OF COMPARABLE CONCEPTS AND DATA ABOUT COLLECTIVE ACTION
}

\author{
Amy Poteete and Elinor Ostrom ${ }^{1}$ \\ 1. INTRODUCTION
}

The scientific community has made considerable progress in understanding variation in collection action. Once the possibility for divergence between individual and social goods was recognized (Hardin 1968; Olson 1971 [1965]), many scholars and policy analysts saw prisoners' dilemmas and tragedies of the commons everywhere. The supposed ubiquity of collective action problems justified nationalization or privatization of renewable natural resources around the world. ${ }^{2}$ Yet, important differences exist among the types of collective action problems that individuals and communities confront. It is important that we begin to identify conditions that facilitate or hinder collective action.

Collective action is not problematic under all circumstances. Problems arise from inadequate information, conflicting interests, or the nature of the good itself. Game theorists have developed a variety of basic games to capture common aspects of social interaction. Several types of collective action problems exist that have relevance for natural resource management. When people lack information, coordination becomes difficult despite common goals (assurance games). Use and maintenance activities need to be coordinated to avoid crowding or achieve economies of scale. If multiple solutions exist to a collective action problem but have different distributional consequences,

\footnotetext{
${ }^{1}$ The IFRI research program involves the study of forests, people, and institutions by a network of Collaborating Research Centers (CRCs) in 13 countries. The Workshop in Political Theory and Policy Analysis and the Center for the Study of Institutions, Population, and Environmental Change are jointly responsible for coordination of this program. Funding from the Ford Foundation, the MacArthur Foundation, and the FAO is gratefully acknowledged.

${ }^{2}$ See Ostrom (1990) for a discussion and critique of these two approaches to natural resource management.
} 
competition over distributional issues can result in failures to cooperate (chicken games).

The beneficiaries of alternative management strategies are often vastly different, for example, making agreement and cooperation difficult to achieve (battle of the sexes games). Rivalry in consumption and difficulty of exclusion make provision and sustenance of common-pool goods particularly challenging (social dilemma games more specifically, common-pool resource games). Obstacles to exclusion encourage individuals to free-ride on the efforts of others. Difficulty of exclusion and rivalry of extraction characterize many natural resource systems, including forests, watersheds, and fisheries. These conditions can result in under-provision of management and degradation of common resources.

Although collective action problems differ in severity, many case studies (Baland and Platteau 2000 [1996]; Bromley, et al. 1992; McCay and Acheson 1990; Ostrom 1990) and evidence from laboratory experiments (Ostrom, Gardner and Walker 1994; Ostrom 2000; Udéhn 1993, 254 - 256) demonstrate that many varieties of collective action problems can be overcome. The on-going challenge is to better understand sources of variation in the success of collective action. A large number of factors have been identified as facilitating collective action, including characteristics of the collective problem, ${ }^{3}$ characteristics of the group, institutional arrangements, technology, and the actions of national governments and other external actors (Ostrom, et al. 2002). ${ }^{4}$

Despite significant progress, many questions about prospects for collective action have yet to be solved. Lists of important variables differ (Agrawal 2001). Debates

\footnotetext{
${ }^{3}$ For natural resource management, characteristics of the resource system greatly influence the nature of the collective problem.

${ }^{4}$ Agrawal (2001) summarizes factors identified as facilitating collective action for management of common-pool resources by Baland and Platteau (2000 [1996]), Ostrom (1990), and Wade (1988).
} 
continue about whether and how particular factors, especially group size and heterogeneity, affect prospects for successful collective action (Agrawal and Goyal 2001; Baland and Platteau 1999; Bardhan and Dayton-Johnson 2002; Gibson and Koontz 1998; Johnson and Libecap 1982; Quiggin 1993; Ruttan and Borgerhoff Mulder 1999; Varughese and Ostrom 2001). And there is little consensus on the relative importance of explanatory factors or the nature and significance of interactions among them. The variety and number of factors associated with successful collective action, while encouraging for social relations, makes analysis difficult.

Efforts to resolve puzzles about collective action through empirical research confront two major obstacles. First, the key factors expected to affect collective action and the outcomes of collective action are inconsistently conceptualized and measured. Inconsistent terminology and measurements may obscure consistent patterns or suggest patterns where none exist. Second, the scarcity of comparable data makes it impossible to evaluate the relative importance of many of the variables identified in the literature as likely to influence collective action. Case studies are extremely important to an understanding that collective action is feasible, but case study authors tend to identify different variables to study and making the findings from case studies comparable is extremely difficult.

Contributions of empirical research to the study of collective action will be limited unless the challenges of conceptual consistency and comparable data can be overcome. This paper describes an ambitious effort to meet these dual challenges: the International Forestry Resources and Institutions (IFRI) research program. To accumulate a large number of cases on a comprehensive set of variables, an international network of 
research centers was created, consisting of scholars committed to using the IFRI protocols in data collection and contributing their data to a common database. To achieve consistency of concepts and empirical measurement, IFRI researchers developed a common set of data collection instruments and common methods of data collection.

The remainder of the paper is organized in five parts. First, we provide an overview of the IFRI research program. The second section concerns the need for comparable data and how the IFRI research strategy helps meet that need by building a sizeable database of comparable cross-national data more quickly than would have been possible for any single researcher or research center. We discuss the challenges of conceptual consistency and empirical measurement, and how researchers have used IFRI protocols to study collective action and various factors expected to influence success, in the third section. Despite the progress made, IFRI continues to struggle with conceptual consistency and the difficulty of analyzing complex processes. The fourth section identifies several such issues. Fifth, we summarize and conclude.

\section{THE INTERNATIONAL FORESTRY RESOURCES AND INSTITUTIONS (IFRI) RESEARCH PROGRAM}

The IFRI research program engages an international network of scholars in longterm, comparative research on forests, the people who use forest resources, and institutions for forest management (Ostrom 1998). ${ }^{5}$ IFRI grew out of on-going efforts to study collective action for the management of common-pool resources. An initial database drew upon existing case studies - mostly about fisheries, groundwater basins, and irrigation systems - and provided the basis for Governing the Commons (Ostrom

\footnotetext{
${ }^{5}$ This section draws heavily on Poteete and Ostrom (forthcoming).
} 
1990). It was followed by the Nepal Institutions and Irrigation Systems (NIIS) database. NIIS began by coding existing case studies, but also used relatively rapid field visits to fill in data points addressed ambiguously or not at all in the original study. An inquiry from the FAO's Forest, Trees, and People Program about the possibility of developing a similar database for forest resources prompted creation of the International Forestry Resources and Institutions (IFRI) research program. IFRI built upon the theoretical framework, empirical findings, and database structure of its two predecessors. IFRI differs considerably from these earlier efforts in its primary reliance on fieldwork rather than existing studies, the shift in attention to more complex and multiple product forest resource systems, and in organization as a research network.

The international research network includes Collaborating Research Centers (CRCs) in Africa, Asia, Latin America, and North America. ${ }^{6}$ IFRI studies encompass a wide array of forests and institutions. With studies in temperate forests in the U.S., the mountain forests of the Himalayas, and tropical moist and tropical dry forests in Africa, Asia, and Latin America, the research program encompasses diverse ecological conditions. IFRI forests range from a one-hectare cultural or sacred forest in Uganda to a Bolivian forest reserve of just under 45,000 hectares. Many IFRI forests are owned and managed by a national government, reflecting the prevalence of state control of natural resources in recent times. Other IFRI forests fall under private or communal ownership. These categories mask further diversity in property arrangements. Communal management, for example, occurs when governments grant villagers formal control, but also when local residents exercise de facto control in the absence of formal rights. A

\footnotetext{
${ }^{6}$ As of March 2003, there are 13 IFRI CRCs in 12 countries (see http://www.indiana.edu/ ifri/crcs.htm). The first were established in 1993. Revisits have begun in Kenya, Nepal, Uganda, and the USA (see Becker and Ostrom 1995; Gombya-Ssembajjwe 1999; Schweick, Adhikari and Nidhi Pandit 1997).
} 
number of IFRI forests, owned as private property by groups of unrelated individuals, do not fit common understandings of private or communal property. A variety of management regimes exist in these forests, ranging from management for timber production, protection for wildlife or biodiversity conservation, to management for multiple uses.

Data collection for the IFRI research program encompasses biophysical measures of forest conditions, climatic and soil conditions, demographic and economic indicators about the population of forest users, as well as details about institutions affecting use of forest resources. IFRI researchers conduct repeat studies of forest sites every three to five years. The interdisciplinary approach allows assessments of hypothesized relationships among biological, demographic, economic, and institutional variables. Analysis of social and institutional processes that take years to unfold becomes possible with the accumulation of time-series data.

IFRI brings to the empirical study of collective action an international database of comparable studies from all over the world, with comparability ensured by the use of a common research framework and methodology.

\section{IFRI AND THE CHALLENGE OF COMPARABLE DATA}

In a recent review of research on common-pool resources, Agrawal (2001) identified 33 separate explanatory factors that have been repeatedly identified in the literature as important. Given the large body of literature confirming the potential influence of each variable, he contends that analysis that excludes any of these factors should at least discuss the likely biases of the missing variables. Inclusion of such a large 
number of variables, however, in most statistical analyses is not feasible, barring the use of Boolean algebra (Ragin 1987) or very large data sets subject to multivariate analysis. Multivariate analysis can incorporate numerous variables, but a much larger number of data points are required to reliably assess relationships.

The empirical complexity of many variables of interest implies that substantial investments in fieldwork are required to obtain reliable data; as a result, scholars have been hard-pressed to build large databases for the study of common-pool resources. Large databases can be built by coding existing studies, as demonstrated by Tang (1992) and Schlager (1994). Since existing empirical studies typically address only a subset of the factors identified in the literature, missing data inevitably limits analysis. This sort of analysis also confronts differences in conceptualization and the empirical measurement of variables by different authors. Some researchers have collected data on relatively large sets of cases (Bardhan 2000; Dayton-Johnson 2000; Lam 1998; Jodha 1990; Shivakoti and Ostrom 2002). Ultimately, since there are limits to the time and financing available for data collection, a trade-off exists between the number and type of variables measured and the number of cases for which data can be collected. Careful sampling can control for some set of factors and limit the degree of bias likely in results. Nonetheless, it may not be possible to control for all variables excluded from data collection and analysis. And controlling for variables leaves many interesting questions un-addressed.

Organization as a network of research centers facilitates comparative research. Members of the IFRI research network collect data on a common set of variables, ${ }^{7}$ use the same methods for data collection, and share data in a growing international database,

\footnotetext{
${ }^{7}$ IFRI represents the core, not the limits, of data collection. Many IFRI research teams collect supplemental data to address specific research questions.
} 
thereby maintaining the comparability required for cross-national analysis. By early 2002, data for 173 sites with 264 forests, 302 forest user groups, and 614 forest products had been entered into IFRI's common database. ${ }^{8}$ The relative breadth of variables included in the IFRI protocols and relatively large number of data points in the database enables more complex multivariate analysis than would otherwise be possible.

\section{THE CHALLENGE OF CONCEPTUAL AND EMPIRICAL CONSISTENCY}

If empirical research is to contribute to further progress in understanding conditions favorable for collective action, greater clarity will need to be achieved in the conceptualization of the unit of analysis, conceptualization of dependent and independent variables, and in how these concepts are operationalized for data collection and analysis.

\section{COLLECTIVE ACTION BY WHOM?}

For most discussions of collective action, "the group" is the unit of analysis. For research concerning natural resources, this means "the group that uses the resource" or "the user group." In theoretical work and empirical studies, the group is often a point of departure rather than subject of inquiry. ${ }^{9}$ Yet, in actual data collection, people do not present themselves to researchers in unambiguously demarcated groups. Rather, empirical researchers have to determine how to conceptualize - and recognize in the field - the relevant set of people for analyzing the problem of collective action.

In the abstract, it is simple enough to say that the relevant group includes individuals who face a collective action problem - which is to say, who share some

\footnotetext{
${ }^{8}$ Updates of the common database occur periodically, as new data comes in from collaborating research centers.

${ }^{9}$ But see Agrawal and Gibson (1999) and Turner (1999) for critical discussions of the concept of "community."
} 
interests in common. In practice, people have a number of interests, even within a single sphere of activity such as natural resource management. Membership in the set of individuals with the potential for collective action depends upon the problem under consideration. Subsets of individuals with an interest in sustaining a resource system may organize to pursue particularistic interests while the more encompassing set of individuals fail to act collectively.

The implications of collective action at one level of aggregation for collective action at other levels of collective interest are not uniform. Consider two examples. Individuals who collect medicinal herbs may organize while those who collect firewood do not. If the herb collectors see the lack of collective action among firewood collectors as a problem for themselves, they may attempt to mobilize collective action at a level that encompasses both groups. If, however, timber harvesters have organized while those using a variety of non-timber forest products (NTFPs) have not, the incentive for timber harvesters to facilitate collective action among all users of forest resources is less apparent. Not all empirical studies about collective action for resource management explicitly address the possibility of multiple levels of collective action. Programs for community-based resource management often assume the presence of a clear community of interest at the level of the resource system. ${ }^{10}$

The IFRI research program uses a modular approach to evaluate the existence and consequences of collective action for forest management. The basic social unit of analysis is the user group, defined as a set of individuals with the same rights and responsibilities to forest resources. This definition does not require formal organization or

\footnotetext{
${ }^{10}$ See Campbell et al. (2001) and Turner (1999) for critiques of community-based programs for resource management. See Agrawal and Gibson $(1999 ; 2001)$ for a more general critique of the use of the term "community" in the literature on natural resource management.
} 
collective action. Groups that have organized institutions for collective decision-making are considered forest associations. Forest associations may bring together more than one user group, although many of studies find a one to one relationship between user groups and forest associations. Recognition that groups with common rights and responsibilities may or may not be involved in collective action or have institutionalized rules for collective decision-making makes it possible to analyze this variation. This strategy for data collection allows analysis of collective action and its absence within groups with comparable rights to resources.

In many forests, IFRI methods identify multiple user groups. Because user groups are defined according to their rights and responsibilities to the forest, the number of user groups says little by itself about the degree of specialization in use of forest products. Two user groups may use different sets of forest products, although overlaps in the products used are common. If a forest association exists in an IFRI site, it may represent one or more user group. Forest associations may encompass a large proportion of forest users, or they may be formed by a subset of forest users. The presence or absence of a forest association is an indication of collective action for the creation of institutions to manage forest resources. By itself, the existence of a forest association does not reveal what proportion of forest users is acting collectively in this manner. The IFRI database includes information about the scope of representation by forest associations, but a researcher would have to dig around a bit to access this data and get it into a form amenable to analysis.

IFRI's distinction between user groups and forest associations greatly facilitates the empirical study of collective action. It provides a common standard unit for observing 
and measuring potential collective action. It also ensures the collection of data about groups that have overcome collective action problems as well as those that have not. Since groups may act collectively for some but not all aspects of forest management, this modular approach to collective action also facilitates analysis that distinguishes among types of collective action (see below). IFRI's use of commonality in rights and responsibility relative to a forest as the defining characteristic of a user group is less helpful for research concerned with the scope of collective action or about the "community" as the social unit of analysis.

\section{IS THIS GROUP ACTING COLLECTIVELY?}

The difficulty of recognizing informal institutions and discerning the effectiveness of formal institutions on forest conditions represents an important challenge for institutional analysis. Biophysical data on forest conditions can be used to discern the effectiveness of collective action for forest management. If forest users have developed rules of forest management, whether formal or informal, and those rules effectively alter behavior (i.e., they are "rules-in-use"), changes will occur in the patterns of forest use. IFRI's research strategy involves the collection of descriptions of rules and evaluations of their effectiveness through interviews and participatory sessions, plus the collection of data on forest conditions. With both social and biophysical data, it becomes possible to check social scientific data about rules for management against biophysical data on forest conditions.

In general, harvesters of forest products are expected to engage in optimal foraging strategies unless rules-in-use constrain their behavior. Optimal foraging implies that humans follow a cost-benefit calculus in their harvesting behavior. First, they will 
use forest products that are the most valuable (in terms of yield minus cost of extraction). When the value of forest products does not vary with location, then optimal foraging implies that the most accessible resources will be harvested first. All else equal, proximity to settlements and to roads lowers the cost of extraction. Steep slopes, impassible rivers, and other physical impediments increase the difficulty of extraction, and are usually utilized after more geographically accessible areas. In the absence of institutions that alter patterns of forest use, the biophysical data should reveal evidence of extraction that reflects proximity and physical accessibility. Smaller, younger trees should be found closer to settlements and roads, and in flatter areas, with larger, older trees deeper in the forest and on steeper slopes. If effective institutions for forest management are in place, however, the institutions alter the cost-benefit calculus. Depending on the nature of the management rules, patterns of harvesting should change in ways that will be measured biophysical data from forest plots. Four recent IFRI studies (Schweik 2000; Banana, Gombya-Ssembajjwe, and Bahati 2001; Becker and Leon 2000; Gibson 2001) compare actual forest conditions with predictions based on optimal foraging theory to evaluate the influence of institutions upon forest conditions.

In Nepal, partial enforcement of national rules for forest conservation had the unintended consequence of shifting extraction from areas near the villages and roads to a more ecologically vulnerable watershed (Schweik 2000). Officials charged with enforcing national policy and the villagers faced the same physical terrain. Because the officials could more readily monitor forest use in areas near the roads, near settlements, and on lower slopes, villagers could count on tighter enforcement in these areas. Data from forest plots revealed that villagers had shifted harvesting activities to the steeper 
slopes further from their settlements. These physically less accessible areas represent a more ecologically vulnerable portion of the forest. Both the forest and the villagers would be better off in the absence of national forest rules than with their current haphazard enforcement.

Likewise, the limited capacity of the Ugandan forest department results in reasonably tight enforcement of a ban on timber harvesting near the capital city, but in consistently high levels of illegal harvesting further away (Banana, Gombya-Ssembajjwe and Bahati 2001). In the absence of rules affecting timber harvesting, one would expect heavier levels of extraction closer to Kampala, because the higher concentration of people in the capital city represents a large market. In the absence of spatial variation in the level of enforcement, the ban should decrease timber harvesting throughout Mpigi district, in which Kampala lies. One would still expect higher levels of illegal harvesting in the vicinity of the capital. The presence of greater evidence of timber harvesting further away from the capital city strongly supports a general sense that levels of enforcement decrease with distance from Kampala.

In Bolivia, deviations from use patterns associated with optimal foraging among the Yuracaré challenged assumptions that such indigenous peoples lack systems for forest management (Becker and Léon 2000). In the early 1990s, the Bolivian government adopted a policy that allows indigenous people to gain formal title to their territories, but requires that they first develop a formal management plan for the forest resources. The policy suggests the absence of indigenous systems for forest management. Data from forests managed by the Yuracaré revealed that they do have an effective system for managing fruit trees, but have not yet devised rules for managing timber resources. 
Building upon the existing system makes more sense in this situation than developing a management plan from scratch, as called for by government policy.

In contrast, evidence that extraction closely matched patterns associated with optimal foraging bolstered Gibson's claim that two villages in Guatemala lacked institutions for forest management (2001). Villagers might not report rules about forest management because they were suspicious of outsiders, or the researchers might fail to recognize informal rules, but the biophysical evidence eases such doubts about the lack of social scientific evidence of rules. Where biophysical evidence of optimal foraging confirms that communities truly lack rules for forest management, external intervention could raise awareness of indirect benefits associated with forest conservation and encourage the development of rules for forest management. After an IFRI study in Loma Alta, Ecuador revealed the absence of local institutions for forest management and a lack of appreciation for the forest's role in watershed protection, a series of participatory studies organized by a non-government organization demonstrated dramatic differences in fog interception associated with variable forest conditions (Becker 1999). The villagers subsequently decided to protect a portion of their forest for watershed management.

\section{COLLECTIVE ACTION FOR WHAT?}

Collective action can take many forms, including the development of institutions (e.g., rules for resource management), resource mobilization (e.g., to hire guards or invest in maintenance activities), coordination of activities (e.g., to avoid crowding), and information sharing (e.g., about techniques or the location of mobile resources). Scholars generally state clearly the nature of collective action under consideration in any particular

analysis, although there is a tendency to claim that findings have broader implications for 
the study of collective action. Efforts to synthesize findings from multiple studies face the challenge of evaluating the analytically relevant similarities and differences among different types of collective action. Even within any category of collective action, such as institutional design or resource mobilization, the difficulty of acting collectively can vary dramatically.

IFRI scholars study various forms of collective action. The studies discussed in the section on optimal foraging were concerned with institutional development in the form of management rules. These scholars were less concerned with the formalization of management rules in a forest association. Other IFRI scholars concerned with collective action for resource management have developed indices that measure aspects of collective action in forest management. Indices developed by both Varughese (1999) and Chakrabarti et al. (2001) recognize the importance of distinguishing between the creation of collective rules and action to implement and enforce collective rules.

Varughese (1999), in a study of 18 sites in Nepal's middle hills, developed an index including the presence of collective rules constraining access to and harvest from forests, organization of group activities related to forest management, and monitoring activities by group members as evidence of collective activity. The presence of group activities and rules for management indicate a moderate level of collective activity; high scores on this index require monitoring of rules for forest access and use. This study found that forest conditions were more closely correlated with levels of collective action than with population pressure.

For analysis of 12 sites in North Bengal, India, Chakrabarti et al. (2001) developed an index based on collective action on a set of 18 forest management activities 
(e.g., planting seedlings, harvesting, marketing of forest products). For this index, a group earns 0.5 points for each management activity for which it has adopted a rule; actual coordination on implementation of collective rules earns 1.0 point per activity. This analysis also found a positive correlation between forest conditions and levels of collective action. Higher levels of collective action were more common in communities with prior experience with self-governance through Panchayati Raj institutions, and in communities with greater heterogeneity in wealth and education.

Another set of studies focuses on collective action for the mobilization of resources required for effective monitoring and enforcement of rules for forest management. Monitoring and enforcement is costly. In some communities, responsibility for guarding rotates among households. Other communities raise funds to hire individuals to guard forest resources on behalf of the community. For the community to hire guards, it must mobilize resources for this collective goal (Agrawal 2000; Agrawal and Goyal 2001). Hiring a guard is a lumpy good; the guard must be retained for a minimal number of months to effectively protect forest resources. A series of articles about forest councils in Kumaon, India measures collective action in terms of resource mobilization as the monetary value of the contribution per household, the group budget for protection, or the number of months each community was able to pay the guard (Agrawal 2000; Agrawal and Goyal 2001). These studies revealed a curvilinear relationship between group size and collective action for resource mobilization: the smallest groups had less success than somewhat larger groups in mobilizing the resources requiring for forest protection.

The IFRI research network has not limited its attention to any single form of collective action. Openness makes the research program attractive to a variety of scholars 
with overlapping but not identical research questions. Diversity of approaches has merit; comparisons of alternative conceptualizations of hypothesized relationship can help advance knowledge more rapidly. The lack of consistency in measurement of collective action does raise the risk of miscommunication between scholars who use the same terms to describe somewhat different phenomena. Clear explanations of variables and how they have been measured offer the best defense against miscommunication.

\section{WHAT AFFECTS COLLECTIVE ACTION?}

The conceptual and empirical challenges related to independent variables that may affect the likelihood of collective action are even more extreme. When scholars debate the importance of group size, for instance, it is not clear that a common frame of reference exists. Is a group of 100 individuals large or small? What about a group of 1000 individuals, or of 50? Likewise, scholars concerned about the implications of heterogeneity for collective active discuss a number of different forms of group diversity (Varughese and Ostrom 2001; Keohane and Ostrom 1995). Many studies on heterogeneity focus on economic inequality, but even economic inequality may refer to either income or assets (Baland and Platteau 1999; Quiggin 1993; Ruttan and Borgerhoff Mulder 1999). Others have examined heterogeneity in values (Gibson and Koontz 1998), of knowledge and skills (Johnson and Libecap 1982), of location (Ostrom 1996; Varughese 1999; Varughese and Ostrom 2001), or of interest in maintaining the resource. It is not at all obvious how one should compare findings from studies that use the same terms for either very different concepts - as with heterogeneity - or for varying classifications of empirical situations - as with group size. 
Even when the concept is clearly agreed upon, differences may arise from operationalization in data collection and analysis. Some concepts are unavoidably subjective. What is an adequate level of monitoring? How much disagreement is consistent with a common understanding? How can the level of trust in a community be determined objectively? In the case of trust and many other variables, measurement is both subjective and indirect. Some conceptual variables have many components empirically. Wealth, for example, may take the form of livestock, capital assets such as houses and tools, and cash. The same concepts may be used to refer to data that reflects different aspects of the same phenomenon. The problem grows all the more complicated when empirical manifestations of a concept, like wealth, are contextual.

The distinction drawn in data collection between user groups and forest associations is characteristic of IFRI's modular approach to data collection. Participants in the design of the IFRI research instruments knew they needed measures for several factors suspected to influence collective action. These included population pressure, group size, market pressure, local autonomy, heterogeneity, economic and subsistence significance of the forest, difficulty of exclusion, and difficulty of understanding how forest resources respond to human actions. For each of these concepts, multiple empirical indicators existed. IFRI data collection protocols were designed to capture multiple indicators of potential concepts of interests, and to do so in a way that allows a number of different combinations.

The lack of consistency in concepts and their empirical measurement represents a major challenge for the accumulation of knowledge about the factors affecting collective action related to resource management. Apparently contradictory findings may not 
actually contradict; apparently similar findings may actually refer to different issues. Synthesis of findings becomes very difficult under these conditions. Without a valid understanding of what is reliably known from past studies, the design of new empirical studies to advance knowledge further becomes quite difficult.

\section{CONTINUING CHALLENGES}

The International Forestry Resources and Institutions research strategy addresses two major challenges to empirical research on collective action. The use of common research instruments and techniques for data collection provide a foundation of conceptual consistency. Organization as a network of research centers results in more rapid accumulation of comparable, cross-national data. Further, data are collected by researchers who are closely familiar with local languages, customs, and ways of organizing. Graduate students associated with IFRI centers inherit a rich source of data for further analysis and contribute to the store for those who follow. It is possible to return to a site at relatively low cost to check out missing data or do a complete follow-up visit.

The IFRI strategy has not eliminated all challenges, nor is it possible to do so. IFRI struggles with the need to balance consistency of concepts and methods throughout the network with the desirability of conceptual and methodological evolution in response to the accumulation of knowledge. The concept of the user group and the problem of identifying group boundaries have particular importance for the study of collective action, and for contributions to policy debates about community-based natural resource 
management. In addition, IFRI is still working toward realization of the full benefits of organization as a network.

The reliability of IFRI's common database relies upon consistency of concepts and methods across research teams. That consistency is reinforced through an annual nine-week training program at Indiana University plus less frequent regional training programs. But insistence on conceptual and methodological consistency runs counter to the evolutionary nature of learning. Knowledge advances through the refinement of concepts and methods in response to findings from past studies. IFRI researchers recognize the need to balance consistency with revision following learning, and are grappling with ways to do so. Biennial meetings of the full network offer opportunities to discuss modifications to the research program. Attitudes toward change have been conservative. Although conservatism limits the ability to incorporate new knowledge guards, it also against the loss of comparability across studies conducted at different times.

IFRI has always allowed researchers to supplement the common core of data collection. By supplementing the core data collection instruments, research teams can try out alternative measurements and methods without endangering comparability on the common variables. Efforts are currently underway to increase communication across the network about various efforts to develop new or alternative measurements. Supplementary measures of interest throughout the network could become candidates for incorporation into the core instruments, perhaps as substitutes for current measures that proved to be less effective. This has not yet occurred. 
Despite the accumulation of IFRI data, only a few IFRI studies have attempted to use data from multiple countries (Poteete 2001; Gibson, Williams, and Ostrom 1999). Many IFRI publications concern either a single case or a paired comparison (Gibson McKean and Ostrom 2000). IFRI colleagues who have completed a larger number of sites have begun to do multivariate analyses, but usually limit themselves to data from their own sites (Agrawal and Yadama 1997; Agrawal and Goyal 2001; Banana, GombyaSsembajjwe and Bahati 2001; Varughese and Ostrom 2001; Varughese 1999). The scarcity of cross-national analysis reflects the difficulty of drawing comparisons across ecological zones, cultures, and political boundaries. Ecological measures of forest condition, such as height or diameter at breast height or species diversity, are strongly affected by a variety of localized ecological conditions and topography. Measurements of healthy forests in the Himalayas, in the moist tropics of Guatemala, and arid tropical areas of Mexico or Uganda will differ considerably on many of these forest mensurations. Comparative analysis that includes forest condition as the dependent variable or as an important independent variable depends upon techniques or proxy measurements that allow comparisons across ecological zones. Even for analyses that do not include biophysical data, differences in culture and policy environment across countries may affect outcomes. Indeed, inclusion of dummy variables for Uganda, the USA, and Nepal revealed noteworthy country-specific effects on efforts by user groups to exclude others from forest resources (Poteete 2001). Limitations to comparability do not make crossnational analysis impossible, but do make it more difficult. The analytical difficulty of cross-national analysis and the possibility of context-specific patterns are just two good 
arguments in favor of a strategy of testing hypotheses first with data from a single country, and then scaling up to cross-national analysis.

The potential of the IFRI network does not depend solely upon an increase in cross-national analysis. Communication about findings within the network enhances their incorporation into the design of future studies. Regular communication about research activities depends upon declining telecommunication costs, especially for internet access, and more frequent opportunities for face-to-face exchange. Regular synthesis of findings identifies emerging themes, disseminate findings to a larger audience, and influence future studies.

\section{CONCLUSIONS}

It is difficult to write a "concluding section" when one is describing the efforts of an on-going research program to solve extremely challenging puzzles that underlie all efforts to build systematic knowledge about collective action. Users of forestry resources are interacting with complexly, adapting ecological systems and are themselves a part of a human, complex, adaptive systems. Both ecological and human systems exist at multiple scales over time. Consequently, the challenge for all researchers and policy analysts is to gain a slow accumulation of knowledge about the processes within these complex systems and how they adapt to change over time.

The International Forestry Resources and Institutions research program is an

effort to use a consistent set of concepts and ways of measuring these concepts in order to facilitate the long-term understanding of collective action processes as related to forests. The effort has already produced a better understanding of how the heterogeneity of users can lead to strong distributional effects (Poteete 2001) that can be offset to some extent 
by rules designed to provide different roles, duties, and benefits to different groups of users (Varughese 1999). We have learned that whether individuals are motivated to think about engaging in collective action is strongly affected by their perceptions of the condition of a resource - not by the "actual" condition (Agrawal 2000; Gibson, Lehoucq, and Williams 2002; Gibson and Becker 2000; Tucker 1999). Those perceptions can in turn be changed by a variety of techniques that give more accurate feedback to users about the functioning of the relevant ecosystem and its condition (Becker 1999). We have learned that distance between a forest and a large urban area has several impacts on forest conditions including the capacity to monitor harvesting rates as well as the cost of transporting forest products (Banana, Gombya-Ssembajjwe and Bahati 2001). And, we have learned many other interesting relationships that we and other scholars will continue to explore in the coming years as we all try to gain clearer conceptions of key variables and processes and find better ways of measuring them. 


\section{REFERENCES}

Agrawal, A. 2001. Common property institutions and sustainable governance of resources. World Development 29 (10): 1623 - 1648.

2000. Small is beautiful, but is larger better? forest-management institutions in the Kumaon Himalaya, India. In People and forests: Communities, institutions, and governance, ed. Clark C. Gibson, Margaret A. McKean, and Elinor Ostrom. Politics, Science, and the Environment. Cambridge, MA: MIT Press.

Agrawal, A and C.C. Gibson. 2001. Communities and the environment. ethnicity, gender, and the state in community-based conservation. New Brunswick, N.J.: Rutgers University Press.

1999. Enchantment and disenchantment: The Role of Community in Natural Resource Conservation. World Development 27 (4): 629-49.

Agrawal, A. and S. Goyal. 2001. Group size and collective action: Third party monitoring in common-pool resources. Comparative Political Studies 34 (1): 63 - 93.

Agrawal, A. and G.N. Yadama. 1997. How do local institutions mediate market and population pressures on resources? Forest Panchayats in Kumaon, India. Development and Change 28 (3): 435 - 465.

Baland, J-M. and J-P. Platteau. 2000 [1996]. Halting degradation of natural resources: Is there a role for rural communities? New York, N.Y.: Oxford University Press.

. 1999. The ambiguous impact of inequality on local resource management. World Development 27 (5): 773 - 788.

Banana, A., W. Gombya-Ssembajjwe, and J. Bahati. 2001. Explaining deforestation: The role of forest institutions in Ugandan forests - A Policy Brief. Kampala: UFRIC, Makerere University.

Bardhan, P. K. 2000. Irrigation and cooperation: An empirical analysis of 48 irrigation communities in south India. Economic Development and Cultural Change 48 (4) (July): 847-865.

Bardhan, P., and J. Dayton-Johnson. 2002. Unequal irrigators: Heterogeneity and commons management in large-scale multivariate research." In The drama of the commons, ed. E. Ostrom, T. Dietz, N. Dolšak, P. C. Stern, S. Stonich and E. U. Weber. Washington, DC: National Academy Press.

Becker, C. D. 1999. Protecting a Garua forest in Ecuador: The role of institutions and ecosystem valuation. Ambio 28 (2) (March): 156-161. 
Becker, C. D. and R. León. 2000. Indigenous forest management in the Bolivian Amazon: Lessons from the Yuracaré people. In People and forests: Communities, institutions, and governance. Cambridge, M.A.: MIT Press.

Becker, C. D. and E. Ostrom. 1995. Human ecology and resource sustainability: The importance of institutional diversity. Annual Review of Ecology and Systematics 26: 113-133.

Bromley, D. W., D. Feeny, M.A. McKean, P. Peters, J. L. Gilles, R.J. Oakerson, C. Ford Runge, and J. T. Thomson, eds. 1992. Making the commons work: Theory, practice, and policy. San Francisco: Institute for Contemporary Studies Press.

Campbell, B., A. Mandondo, N. Nemarundwe, and B. Sithole. 2001. Challenges to proponents of common property resource systems: Despairing voices from the social forests of Zimbabwe. World Development 29 (4): 589-600.

Chakrabarti, M., S. Khaling, J. Bhattacharya, S. Ranjan Ghosh, A. Sarkar, and A. Sarkar. 2001. Functioning of joint forest management in the forests of North Bengal: Observation from 12 IFRI Sites. Paper presented at a Dissemination Seminar, St. Joseph's College, Darjeeling, India, December 2001.

Dayton-Johnson, J. 2000. Choosing rules to govern the commons: A model with evidence from Mexico. Journal of Economic Behavior and Organization 42: 19-41.

Gibson, C. 2001. Forest resources: Institutions for local governance in Guatemala. In Protecting the commons: A framework for resource management in the Americas, ed. J. Burger, E. Ostrom, R. B. Norgaard, D. Policansky, and B.D. Goldstein. Washington, D.C.: Island Press.

Gibson, C. C., and C. D. Becker. 2000. A lack of institutional demand: Why a strong local community in westernEecuador fails to protect its forest. In People and forests: Communities, institutions, and governance, ed. Clark C. Gibson, Margaret A. McKean, and Elinor Ostrom. Cambridge, M.A.: MIT Press.

Gibson, C. C., and T. Koontz. 1998. When 'community' is not enough: institutions and values in community-based forest management in southern Indiana. Human Ecology 26 (4): 621 - 647.

Gibson, C., F. Lehoucq, and J. Williams. 2002. Does privatization protect natural resources? Property rights and forests in Guatemala. Social Science Quarterly 83(1) (March): 206-225.

Gibson, C. C., M. A. McKean, and E. Ostrom. 2000. People and forests: Communities, institutions, and governance. Cambridge, M.A.: The MIT Press.

Gibson, C. C., J. Williams, and E. Ostrom. 1999. Does social capital matter? Communities, governance, and forest resources. Paper presented at the 
International Studies Association Meetings in Washington, D.C. February 17-20 1999.

Gombya-Ssembajjwe, W. 1999. Institutions and sustainable forest management. The Uganda Journal 45: 51-60.

Hardin, G. 1968. The tragedy of the commons. Science 162: 1243 - 1248.

Jodha, N. S. 1990. Rural common property resources: Contributions and crisis, society for promotion of wastelands development. Foundation Day Lecture, May 16 1990.

Johnson, R.N. and G.D. Libecap. 1982. Contracting problems and regulation: The case of the fishery. American Economic Review 72 (5): 1005 - 1022.

Keohane, R. and E. Ostrom. 1995. Local commons and global interdependence. Heterogeneity and cooperation in two domains. London: Sage Publications.

Lam, W.F. 1998. Governing irrigation systems in Nepal: Institutions, infrastructure, and collective action. Oakland, C.A.: ICS Press.

McCay, B.J. and J.M. Acheson, eds. 1990. The question of the commons: The culture and ecology of communal resources. Arizona Studies in Human Ecology. Tucson, AZ: The University of Arizona Press.

Olson, M. 1971 [1965]. The logic of collection action: Public goods and the theory of groups. Harvard Economic Studies. Cambridge, MA and London: Harvard University Press.

Ostrom, E. 2000. Collective action and the evolution of social norms. Journal of Economic Perspectives 14 (3): 137 - 158.

1998. The International Forestry Resources and Institutions Research Program: A Methodology for Relating Human Incentives and Actions on Forest Cover and Biodiversity, pages 1-28 in F Dallmeier and J. A. Comiskey, eds., Forest Biodiversity in North Central and South America, and the Caribbean: Research and Monitoring. Man and the Biosphere Series, vol. 21. Paris: UNESCO; New York: Parthenon.

1996. Incentives, rules of the game, and development. Proceedings of the Annual World Bank Conference on Development Economics 1995. Washington, D.C.: The World Bank.

1990. Governing the commons: The evolution of institutions for collective action, political economy of institutions and decisions. Cambridge and New York: Cambridge University Press. 
Ostrom, E., R. Gardner, and J. Walker. 1994. Rules, games, and common-pool resources, with Arun Agrawal, William Blomquist, Edella Schlager, and Shui Yan Tang. Ann Arbor, M.I.: The University of Michigan Press.

Ostrom, E., T. Dietz, N. Dolsak, P. C. Stern, S. Stonich and E. Weber. 2002. The drama of the Commons. Washington, D.C.: National Academy Press.

Poteete, A. R. 2001. Strategies for regulating use of forest resources: How exclusive? Paper presented at a colloquium at the Workshop in Political Theory and Policy Analysis, Indiana University, Bloomington, IN, October 82001.

Poteete, A. R. and E. Ostrom. Forthcoming. An institutional approach to the study of forest resources. In Human impacts on tropical forest biodiversity and genetic resources, ed. J. Poulsen. New York, N.Y.: CABI Publisher.

Quiggin, J. 1993. Common property, equality, and development. World Development 21 (7): $1123-1138$.

Ragin, C. C. 1987. The comparative method: Moving beyond qualitative and quantitative strategies. Berkeley and London: University of California Press.

Ruttan, L. M., and M. Borgerhoff Mulder. 1999. Are East African pastoralists truly conservationists? Current Anthropology 40 (5): 621-652.

Schlager, E. 1994. Fishers' institutional responses to common-pool resource dilemmas. In Rules, games, and common-pool resources, ed. Elinor Ostrom, Roy Gardner and James Walker. Ann Arbor: University of Michigan Press. Pp. 247-266.

Schweik, C.M. 2000. Optimal foraging, institutions, and forest change: A case from Nepal. In People and forests: Communities, institutions, and governance, ed. C.C. Gibson, M.A. McKean, and E. Ostrom Cambridge, M.A.: MIT Press.

Schweik, C. M., K. Adhikari, and K. Nidhi Pandit. 1997. Land-cover change and forest institutions: A comparison of two sub-basins in the southern Siwalik hills of Nepal. Mountain Research and Development 17(2): 99-116.

Shivakoti, G/ P. and E. Ostrom. 2002. Improving irrigation governance and management in Nepal. Oakland: ICS Press.

Tang, S. Y. 1992. Institutions arrangements and the management of common-pool resources. San Francisco, C.A.: ICS Press.

Tucker, C. M. 1999. Private versus common property forests: Forest conditions and tenure in a Honduran community. Human Ecology 27 (2): 201 - 230.

Turner, M. D. 1999. Conflict, environmental change, and social institutions in dryland Africa: Limitations of the community resource management approach. Society and Natural Resources 12: 643 - 657. 
Udéhn, L. 1993. Twenty-five years with the logic of collective action. Acta Sociologica 36 (3): 239 - 261.

Varughese, G. 1999. Villagers, bureaucrats, and forests in nepal: designing governance for a complex resource. Ph.D. diss. Bloomington, I.N.: Indiana University.

Varughese, G. and E. Ostrom. 2001. The contested role of heterogeneity in collective action: Some evidence from community forestry in Nepal. World Development 29 (5): 747-765.

Wade, R. 1988. Village republics: Economic conditions for collective action in south India. Oakland, CA: ICS Press. 


\section{LIST OF CAPRi WORKING PAPERS}

01 Property Rights, Collective Action and Technologies for Natural Resource

Management: A Conceptual Framework, by Anna Knox, Ruth Meinzen-Dick, and Peter Hazell, October 1998.

02 Assessing the Relationships Between Property Rights and Technology Adoption in Smallholder Agriculture: A Review of Issues and Empirical Methods, by Frank Place and Brent Swallow, April 2000.

03 Impact of Land Tenure and Socioeconomic Factors on Mountain Terrace Maintenance in Yemen, by A. Aw-Hassan, M. Alsanabani and A. Bamatraf, July 2000.

04 Land Tenurial Systems and the Adoption of a Mucuna Planted Fallow in the Derived Savannas of West Africa, by Victor M. Manyong and Victorin A. Houndékon, July 2000.

05 Collective Action in Space: Assessing How Collective Action Varies Across an African Landscape, by Brent M. Swallow, Justine Wangila, Woudyalew Mulatu, Onyango Okello, and Nancy McCarthy, July 2000.

06 Land Tenure and the Adoption of Agricultural Technology in Haiti, by Glenn R. Smucker, T. Anderson White, and Michael Bannister, October 2000.

07 Collective Action in Ant Control, by Helle Munk Ravnborg, Ana Milena de la Cruz, María Del Pilar Guerrero, and Olaf Westermann, October 2000.

08 CAPRi Technical Workshop on Watershed Management Institutions: A Summary Paper, by Anna Knox and Subodh Gupta, October 2000.

09 The Role of Tenure in the Management of Trees at the Community Level:

Theoretical and Empirical Analyses from Uganda and Malawi, by Frank Place and Keijiro Otsuka November 2000.

10 Collective Action and the Intensification of Cattle-Feeding Techniques a Village Case Study in Kenya's Coast Province, by Kimberly Swallow, November 2000.

11 Collective Action, Property Rights, and Devolution of Natural Resource Management: Exchange of Knowledge and Implications for Policy, by Anna Knox and Ruth MeinzenDick, January 2001. 
12 Land Dispute Resolution in Mozambique: Evidence and Institutions of Agroforestry Technology Adoption, by John Unruh, January 2001.

13 Between Market Failure, Policy Failure, and "Community Failure": Property Rights, Crop-Livestock Conflicts and the Adoption of Sustainable Land Use Practices in the Dry Area of Sri Lanka, by Regina Birner and Hasantha Gunaweera, March 2001.

14 Land Inheritance and Schooling in Matrilineal Societies: Evidence from Sumatra, by Agnes Quisumbing and Keijuro Otsuka, May 2001.

15 Tribes, State, and Technology Adoption in Arid Land Management, Syria, by Rae, J, Arab, G., Nordblom, T., Jani, K., and Gintzburger, G., June 2001.

16 The Effects of Scales, Flows, and Filters on Property Rights and Collective Action in Watershed Management, by Brent M. Swallow, Dennis P. Garrity, and Meine van Noordwijk, July 2001.

17 Evaluating Watershed Management Projects, by John Kerr and Kimberly Chung, August 2001.

18 Rethinking Rehabilitation: Socio-Ecology of Tanks and Water Harvesting in Rajasthan, North-West India, by Tushaar Shah and K.V.Raju, September 2001.

19 User Participation in Watershed Management and Research, by Nancy Johnson, Helle Munk Ravnborg, Olaf Westermann, and Kirsten Probst, September 2001.

20 Collective Action for Water Harvesting Irrigation in the Lerman-Chapala Basin, Mexico, by Christopher A. Scott and Paul Silva-Ochoa, October 2001.

21 Land Redistribution, Tenure Insecurity, and Intensity of Production: A Study of Farm Households in Southern Ethiopia, by Stein Holden and Hailu Yohannes, October 2001.

22 Legal Pluralism and Dynamic Property Rights, by Ruth Meinzen-Dick and Rajendra Pradhan, January 2002.

23 International Conference on Policy and Institutional Options for the Management of Rangelands in Dry Areas, by Tidiane Ngaido, Nancy McCarthy, and Monica Di Gregorio, January 2002.

24 Climatic Variablity and Cooperation in Rangeland Management: A Case Study From Niger, by Nancy McCarthy and Jean-Paul Vanderlinden, September 2002. 
25 Assessing the Factors Underlying the Differences in Group Performance:

Methodological Issues and Empirical Findings from the Highlands of Central Kenya, by Frank Place, Gatarwa Kariuki, Justine Wangila, Patti Kristjanson, Adolf Makauki, and Jessica Ndubi, November 2002.

26 The Importance of Social Capital in Colombian Rural Agro-Enterprises, by Nancy Johnson, Ruth Suarez, and Mark Lundy, November 2002.

27 Cooperation, Collective Action and Natural Resources Management in Burkina Faso:A Methodological Note, by Nancy McCarthy, Céline Dutilly-Diané, and Boureima Drabo, December 2002.

28 Understanding, Measuring and Utilizing Social Capital: Clarifying Concepts and Presenting a Field Application from India, by Anirudh Krishna, January 2003. 